\title{
ADSORÇÃO DO CORANTE AMARELO CREPÚSCULO EM LEITO FIXO POR ESFERAS RECOBERTAS COM QUITOSANA DE DIFERENTES GRAUS DE DESACETILAÇÃO
}

\author{
M. L. G. VIEIRA ${ }^{1}$, M. S. MARTINEZ ${ }^{1}$, G. B. SANTOS $^{1}$, V. A. VIEIRA ${ }^{1}$, C. M. MOURA ${ }^{2}$, \\ G. L. DOTTO ${ }^{3}$, L. A. A. PINTO ${ }^{1}$ \\ ${ }^{1}$ Universidade Federal do rio Grande, Escola de Química e Alimentos \\ ${ }^{2}$ Universidade Federal do Pampa, Engenharia de Alimentos \\ ${ }^{3}$ Universidade Federal Santa Maria, Departamento de Engenharia Química \\ E-mail para contato: catarinamoura@unipampa.edu.br
}

\begin{abstract}
RESUMO - A quitosana tem se destacado como um eficaz adsorvente, e a sua imobilização em suportes inertes tem se mostrado promissora para a aplicação nos processos de adsorção em colunas de leito fixo. Este trabalho avaliou, a influência do grau de desacetilação (GD) da quitosana no recobrimento de esferas de vidro e na adsorção do corante amarelo crepúsculo em leito fixo. O efeito do GD (75\%, 85\% e 95\%) foi verificado através da massa de quitosana aderida nas esferas e das curvas de ruptura. As condições de operação da coluna foram vazão $5 \mathrm{~mL} / \mathrm{min}, \mathrm{pH} 3$ e $25^{\circ} \mathrm{C}$. Os melhores resultados, tanto para o recobrimento quanto para o desempenho da coluna, foram obtidos para a quitosana GD 85\%. Nesta condição, a massa de quitosana aderida foi de 0,26 $\mathrm{g}_{\mathrm{qts}} / 100 \mathrm{~g}_{\text {esf, }}$ e a coluna teve os maiores tempos de ruptura $\left(t_{b}\right)$ e de exaustão $\left(t_{e}\right)$, bem como um maior volume de efluente $\left(V_{e f}\right)$ foi tratado. Além disso, a massa total de corante adsorvido foi de $72 \mathrm{mg}$ e o percentual de corante removido chegou a $57 \%$.
\end{abstract}

\section{INTRODUÇÃO}

O corante amarelo crepúsculo é um azo-composto utilizado como aditivo na indústria de alimentos. Embora seja permitido pela legislação brasileira, há relatos de vários efeitos adversos na saúde (Amin et al., 2010). Além disso, a disposição ambiental de efluentes coloridos (como o amarelo crepúsculo) desequilibra as atividades fotossintéticas do meio aquático. Entre os métodos com aplicabilidade no tratamento de efluentes industriais contendo corantes, ressalta-se a adsorção pela possibilidade de utilizar adsorventes de baixo custo (Gupta e Suhas, 2009).

A quitosana possui características interessantes que fazem dela um eficaz adsorvente para a remoção de corantes. Comparada com adsorventes convencionais, tais como carvões ativados comerciais, a adsorção utilizando quitosana tem sido reconhecida (Gupta e Suhas, 2009). A quitosana pode ser imobilizada em matrizes sólidas através de técnicas de recobrimento, e posteriormente aplicada na remoção de corantes em coluna de leito fixo (Popuri et al., 2009).

O recobrimento por imersão, técnica dip coating, destaca-se por ser de simples operação e curto 
tempo de processamento (Jittavanich et al., 2010). As esferas de vidro podem servir como suporte para imobilização da quitosana, basta uma limpeza com solução ácida para neutralizar os compostos alcalinos e óxidos básicos dissolvidos no vidro, formando uma camada superficial rica em sílica, a qual irá interagir com os grupos funcionais da quitosana (Vijaya et al., 2008). Quanto ao processo de adsorção em leito fixo pode-se ressaltar que possui um baixo investimento inicial e alta eficiência se comparado aos processos convencionais, tais como, troca iônica, irradiação, precipitação, ozonização, filtração em membranas e destruição eletroquímica (Ahmad e Hameed, 2010).

O objetivo deste trabalho foi avaliar a influência do grau de desacetilação (GD) da quitosana no recobrimento de esferas de vidro e na adsorção do corante amarelo crepúsculo em leito fixo. A quitosana foi obtida em diferentes graus de desacetilação e caracterizada. As esferas foram recobertas com quitosana pela técnica dip coating. O desempenho do leito foi avaliado mediante as curvas de ruptura.

\section{MATERIAL E MÉTODOS}

\subsection{Adsorvato}

Foi utilizado como adsorvato o corante alimentício da classe química dos azo-corantes, amarelo crepúsculo, proveniente da Duas Rodas Ind., Brasil. Este corante tem como especificações: índice de cor (C.I.) de 15985, massa molar de 452,4 g/mol e comprimento de onda máximo de $480 \mathrm{~nm}$. A sua estrutura química está apresentada na Figura 1.

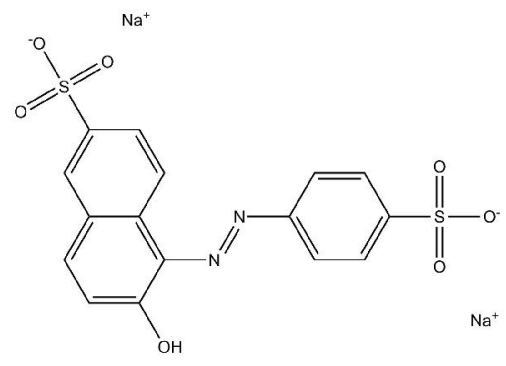

Figura 1 - Estrutura química do corante amarelo crepúsculo.

\subsection{Obtenção da quitosana}

A quitina foi obtida de resíduos de camarão (Penaeus brasiliensis) conforme descrito por Weska et al. (2007). A desacetilação da quitina foi realizada em um reator de pequena escala, utilizando 45 g (b.s.) de quitina seca e $3 \mathrm{~L}$ de solução de hidróxido de sódio (42,1\% p/v), sob agitação constante $(50 \mathrm{rpm})$ e temperatura de $130 \pm 2^{\circ} \mathrm{C}$. Foram realizadas bateladas em diferentes tempos de reação de 40, 90 e 240 min para obtenção de quitosana com grau de desacetilação de $75 \%, 85 \%$ e $95 \%$, respectivamente (Moura et al.,2011). A viscosidade reduzida da quitosana foi determinada pela equação de Huggins e após esta foi convertida em massa molar por meio da equação de MarkHouwink-Sakurada (Zhang e Neau, 2001). O grau de desacetilação (GD) foi determinado pelo 
método de titulação potenciométrica linear (Jiang et al., 2003).

\subsection{Obtenção das esferas recobertas}

As esferas de vidro (diâmetro de partícula de $1 \mathrm{~mm}$ ) foram fornecidas pela Nacional Esferas Ltda., Brasil. As esferas recobertas com quitosana foram obtidas através da técnica dip coating. As esferas foram imersas em solução de quitosana $(0,5 \% \mathrm{~m} / \mathrm{v})$ por $12 \mathrm{~h}$, à temperatura ambiente. Após, as esferas foram separadas da solução por filtração (Vijaya et al., 2008). Então, a secagem da solução de quitosana superficial das esferas foi realizada em estufa a $50^{\circ} \mathrm{C}$ por $12 \mathrm{~h}$ (Wan et al., 2010). $\mathrm{Na}$ sequencia, as esferas recobertas e secas foram imersas em solução de $\mathrm{NaOH} 1 \mathrm{M}$ por $4 \mathrm{~h}$ à temperatura ambiente (Vijaya et al., 2008). A massa de quitosana aderida nas esferas foi determinada por diferença entre a massa de esferas antes e após o processo de recobrimento, em balança analítica (Marte, AY220, Brasil).

\subsection{Ensaios de adsorção em coluna}

O leito fixo foi composto por uma coluna acrílica de $20 \mathrm{~cm}$ de altura e 3,4 cm de diâmetro interno. O leito foi empacotado com esferas recobertas com quitosana de diferentes graus de desacetilação. A solução de corante $(100 \mathrm{mg} / \mathrm{L})$ foi bombeada em fluxo ascendente na vazão de 5 $\mathrm{mL} / \mathrm{min}, \mathrm{pH} 3$ e temperatura ambiente. Foram retiradas amostras no topo da coluna em tempos préestabelecidos até a completa saturação do sistema, sendo a concentração remanescente do corante determinada por espectrofotometria no comprimento de onda máximo do corante.

\subsection{Análise dos dados da coluna}

As curvas de ruptura foram expressas em termos de concentração normalizada $\left(C_{t} / C_{0}\right)$ como uma função do tempo. Os tempos de ruptura $\left(t_{b}\right)$ e de exaustão $\left(t_{e}\right)$ foram definidos quando a concentração na saída da coluna atingiu valores de, respectivamente, $5 \%$ e $95 \%$ da concentração inicial do corante. $\mathrm{O}$ volume de efluente $\left(V_{e f}\right)$ foi calculado pela Equação 1 (Chen et al., 2012).

$$
V_{\text {ef }}=Q t_{\text {total }}
$$

A quantidade total de corante $\left(q_{\text {total }}\right)$ na coluna foi calculada a partir da área da curva de ruptura conforme a Equação 2 (Ahmad e Hameed, 2010).

$$
q_{\text {total }}=\frac{Q}{1000} \int_{t=0}^{t=t o t a l} C_{a d} d t
$$

A capacidade de adsorção do corante no equilíbrio, $q_{e q}(\mathrm{mg} / \mathrm{g})$ foi obtida através da Equação 3 (Han et al., 2009). 


$$
q_{e q}=\frac{q_{\text {total }}}{m}
$$

A massa total de corante alimentada $\left(m_{\text {total }}\right)$ foi calculada pela Equação 4 e o percentual de remoção $(\% R$ ) pela Equação 5 (Han et al., 2009).

$$
\begin{aligned}
& m_{\text {total }}=\frac{C_{0} Q t_{\text {total }}}{1000} \\
& R(\%)=\frac{q_{\text {total }}}{m_{\text {total }}} 100
\end{aligned}
$$

\section{RESULTADOS E DISCUSSÃO}

\subsection{Caracterização da quitosana}

A quitosana obtida em diferentes tempos de reação foi caracterizada quanto o grau de desacetilação, a viscosidade intrínseca e a massa molar conforme Tabela 1.

Tabela 1 - Grau de desacetilação, massa molar e viscosidade intrínseca da quitosana

\begin{tabular}{cccc}
\hline $\begin{array}{c}\text { Tempo de } \\
\text { reação } \\
(\mathrm{min})\end{array}$ & $\begin{array}{c}\text { Grau de } \\
\text { desacetilação } \\
(\%)^{*}\end{array}$ & $\begin{array}{c}\text { Viscosidade } \\
\text { intrínseca } \\
(\mathrm{mL} / \mathrm{g})^{*}\end{array}$ & $\begin{array}{c}\text { Massa molar } \\
(\mathrm{kDa})^{*}\end{array}$ \\
\hline 40 & $75,1 \pm 1,2$ & $165,2 \pm 2,4$ & $215,6 \pm 3,4$ \\
90 & $85,0 \pm 1,0$ & $114,9 \pm 3,6$ & $146,0 \pm 5,0$ \\
240 & $94,7 \pm 0,8$ & $96,7 \pm 3,1$ & $121,2 \pm 4,2$ \\
\hline
\end{tabular}

*Média \pm desvio padrão $(\mathrm{n}=3)$.

Pode-se observar na Tabela 1 que foram obtidas quitosanas com diferentes graus de desacetilação. Isto se deve ao rompimento gradual das unidades N-acetil-D-glucosamina do polímero durante o curso da desacetilação. As unidades de D-glicosamina formadas contém um grupo amínico livre, aumentando a proporção deste na estrutura do polímero. Com o aumento do grau de desacetilação há uma redução no valor da massa molar (Tabela 1) devido à degradação ocorrida nas cadeias do polímero durante a reação. Em relação viscosidade do polímero, pode-se observar comportamento diretamente proporcional ao da massa molar. Os valores de grau de desacetilação e massa molar se assemelham aos obtidos em estudo cinético da reação de desacetilação realizado Moura et al. (2011). 


\subsection{Ensaios de recobrimento}

O efeito do grau de desacetilação da quitosana $(75 \%, 85 \%$ e $95 \%)$ sobre o recobrimento das esferas, e sobre a adsorção em coluna de leito fixo foi verificado através da massa de quitosana aderida nas esferas e das curvas de ruptura, respectivamente. A massa de quitosana aderida nas esferas está apresentada na Tabela 2.

Tabela 2 - Relação entre a massa de quitosana recoberta e a massa de esferas obtida em diferentes graus de desacetilação.

\begin{tabular}{cc}
\hline Grau de desacetilação & Massa de quitosana recoberta $(\mathrm{g} / 100 \mathrm{~g})^{{ }^{\mathrm{a}}}$ \\
\hline GD 75\% & $0,2044 \pm 0,0049^{\mathrm{a}}$ \\
GD 85\% & $0,2633 \pm 0,0120^{\mathrm{b}}$ \\
GD 95\% & $0,1936 \pm 0,0064^{\mathrm{a}}$ \\
\hline
\end{tabular}

g de quitosana/100 g de esferas; ${ }^{a}$ média \pm desvio padrão $(n=3)$. Letras iguais indicam que não existe diferença significativa $(\mathrm{p}>0.05)$; letras diferentes indicam que existe diferença significativa $(\mathrm{p}<0.05)$.

Pode-se verificar na Tabela 2 que o grau de desacetilação da quitosana teve influência significativa $(\mathrm{p}<0,05)$ sobre a massa de quitosana recoberta. Os melhores resultados para o recobrimento foram atingidos com quitosana de grau de desacetilação (GD 85\%). Com isto, pode-se inferir que a adesão da quitosana ao vidro teve influência tanto das propriedades físicas, como a viscosidade da quitosana, quanto das propriedades químicas, como os grupos amina disponíveis para interagir com o vidro. Neste caso, as propriedades citadas foram igualmente importantes no recobrimento, uma vez que a maior massa de quitosana recoberta foi obtida no grau de desacetilação intermediário. Brinker et al. (1992), em estudo sobre a formação de filmes finos através da técnica de recobrimento dip coating salienta que a espessura da película depositada é relacionada com as forças do filme.

\subsection{Ensaios de adsorção em coluna}

As curvas de ruptura estão apresentadas na Figura 2, e os dados fornecidos pelas mesmas sobre a adsorção em coluna de leito fixo estão apresentados na Tabela 3.

Podemos observar através da Figura 2 que a coluna de leito fixo teve o melhor desempenho quando empacotada com esferas recobertas por quitosana GD $85 \%$, seguida pela quitosana GD $75 \%$ e GD 95\%. Neste caso, pode-se inferir que o fator que predominou foi à massa de quitosana presente no leito, tendo em vista que os valores de massa de quitosana aderida nas esferas seguem a ordem GD 85\% > GD 75\% > GD 95\% (Tabela 2). Nos parâmetros fornecidos pelas curvas de ruptura, conforme mostra a Tabela 3, pode-se salientar que ao utilizar quitosana GD 85\% obteve-se maiores tempos de ruptura $\left(t_{b}\right)$ e exaustão $\left(t_{e}\right)$, bem como um maior volume de efluente $\left(V_{e f}\right)$ foi tratado. Além disso, a 
massa total de corante adsorvido chegou a $72 \mathrm{mg}$. Em estudos de adsorção de íons $\mathrm{Cu}$ (II) e Ni (II) por PVC revestido por quitosana, Popuri et al. (2009) observou que as percentagens de remoção aumentaram com o aumento da massa do adsorvente.

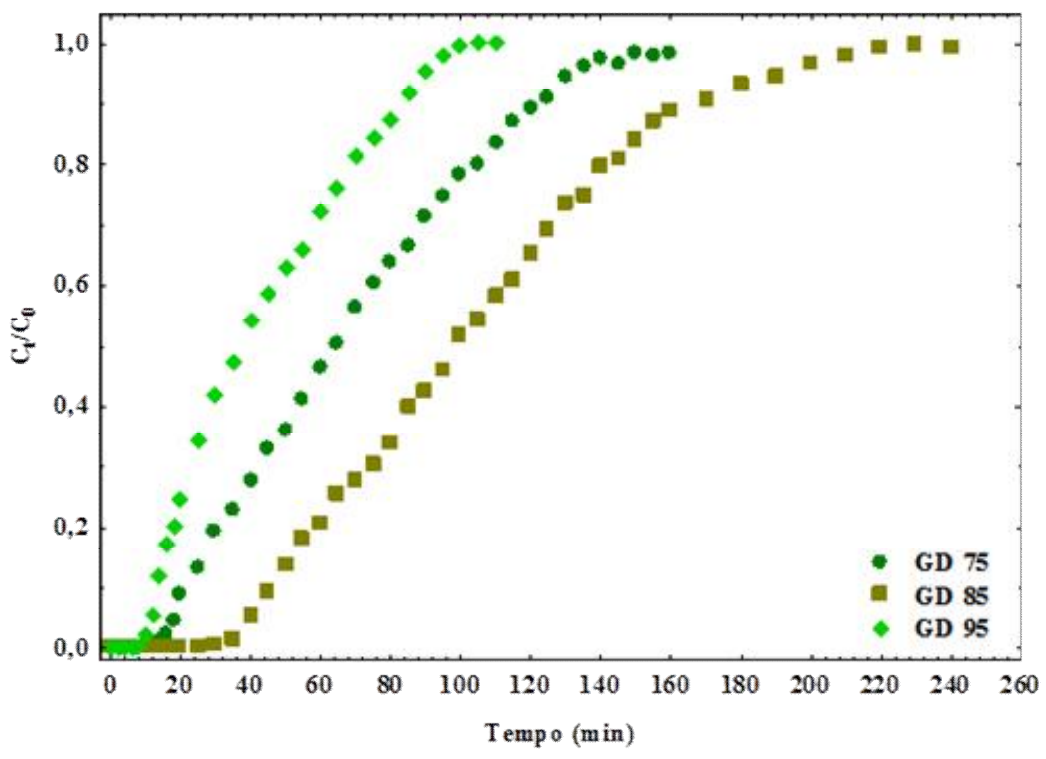

Figura 2 - Curvas de ruptura para a adsorção do corante amarelo crepúsculo por esferas recobertas com quitosana (•) GD 75\% ( $\bullet$ ) GD 85\% (४) GD 95\%.

Tabela 3 - Parâmetros para adsorção do corante amarelo crepúsculo em coluna de leito fixo por esferas recobertas por quitosana de diferentes graus de desacetilação

\begin{tabular}{cccc}
\hline Grau de desacetilação & GD 75\% & GD 85\% & GD 95\% \\
\hline$t_{b}(\mathrm{~min})^{*}$ & $18 \pm 2$ & $40 \pm 5$ & $12 \pm 2$ \\
$t_{e}(\mathrm{~min})^{*}$ & $135 \pm 5$ & $200 \pm 5$ & $90 \pm 5$ \\
$t_{\text {total }}(\mathrm{min})^{*}$ & $160 \pm 5$ & $250 \pm 10$ & $110 \pm 5$ \\
$V_{\text {eff }}(\mathrm{mL})^{*}$ & $800 \pm 25$ & $1250 \pm 50$ & $550 \pm 25$ \\
$q_{\text {total }}(\mathrm{mg})^{*}$ & $46,0 \pm 2,4$ & $72,1 \pm 4,1$ & $33,7 \pm 2,5$ \\
$q_{\text {eq }}(\mathrm{mg} / \mathrm{g})^{*}$ & $81,6 \pm 4,3$ & $99,2 \pm 5,6$ & $63,0 \pm 4,7$ \\
$R(\%)^{*}$ & $57,3 \pm 1,2$ & $57,5 \pm 4,7$ & $60,9 \pm 1,8$ \\
\hline
\end{tabular}

*Média \pm desvio padrão $(\mathrm{n}=3)$. 


\section{CONCLUSÃO}

O recobrimento das esferas mostrou-se mais adequado com quitosana GD 85\%. Nesta condição, a massa de quitosana aderida foi de $0,26 \mathrm{~g}_{\mathrm{qts}} / 100 \mathrm{~g}_{\text {esf }}$. $\mathrm{O}$ mesmo comportamento foi observado para $\mathrm{o}$ desempenho da coluna quando empacotada com esferas recobertas com quitosana GD 85\%, sendo que a massa total de corante adsorvido foi de $72 \mathrm{mg}$ e o percentual de corante removido chegou a $57 \%$. Desta forma, a quitosana aderida em esferas mostrou-se viável para aplicação na remoção do corante amarelo crepúsculo em processos de adsorção contínuos.

\section{NOMENCLATURA}

Símbolo
$C_{a d}$
$C_{o}$
$C . I$.
$M$
$m_{\text {total }}$
$q_{\text {total }}$
$Q e q$
$Q$
$R$
$t_{b}$
$t_{e}$
$t_{\text {total }}$
$V_{\text {ef }}$
$\lambda_{\text {máx }}$

Unidade
$\mathrm{mg} / \mathrm{L}$
$\mathrm{mg} / \mathrm{L}$
-
$\mathrm{g}$
$\mathrm{mg}$
$\mathrm{mg}$
$\mathrm{mg} / \mathrm{g}$
$\mathrm{mL} / \mathrm{min}$
$\%$
$\mathrm{~min}$
$\mathrm{~min}$
$\mathrm{~min}$
$\mathrm{~mL}$
$\mathrm{~nm}$

\section{REFERÊNCIAS}

AHMAD, A. A.; HAMEED, B. H. Fixed-bed adsorption of reactive azo dye onto granular activated carbon prepared from waste. J. Hazard. Mater., v.75, p. 298-303, 2010.

AMIN, K.A.; ABDEL HAMEID II; ELSTTAR, A.H. Effect of food azo dyes tartrazine and carmoisine on biochemical parameters related to renal, hepatic function and oxidative stress biomarkers in young male rats. Food Chem. Toxicol., v. 48, p. 2994-2999, 2010.

BRINKER,C. J.; HURD, A. J.;SCHUNK, P. R.; FRYE, G. C.; ASHLEY, C. S. Review of sol-gel thin film formation. J. Non-Cryst. Solids, v.148, p. 424-436, 1992.

CHEN, S.; YUE, Q.; GAO, B.; LI, Q.; XU, X.; FU, K. Adsorption of hexavalent chromium from aqueous solution by modified corn stalk: A fixed-bed column study. Biores. Technol., v.113, p. $114-120,2012$.

GUPTA, V.K.; SUHAS. Application of low-cost adsorbents for dye removal - A review. J. Environ. 
Manage., v.90, p. 2313-2342, 2009.

HAN, R.; YU, W.; XIN, Z.; YUANFENG, W.; FULING, X.; JUNMEI, C.; NGSHENG, T. Adsorption of methylene blue by phoenix tree leaf powder in a fixed-bed column: experiments and prediction of breakthrough curves. Desalination, v.245, p. 284 - 287, 2009.

JITTAVANICH, K.; CLEMONS C. K.L.; ALJARRAH M.; EVANS E.; YOUNG G.W. Modeling, simulation and fabrication of coated structure using the dip coating technique. Chem. Eng. Sci., v. 65, p. 6169-6180, 2010.

JIANG, X.; CHEN, L.; ZHONG, W. A new linear potentiometric titration method for the determination of deacetylation degree of chitosan. Carbohydr. Polym., v. 54, p. 457-463, 2003.

MOURA, C.M.; MOURA, J.M.; SOARES, N.M.; PINTO, L.A.A. Evaluation of molar weight and deacetylation degree of chitosan during chitin deacetylation reaction: Used to produce biofilm. Chem. Eng. Process., v. 50, p. 351-355, 2011.

POPURI, R. S.; VIJAYA, Y; BODDU, M. V.; ABBURI, K. Adsorptive removal of copper and nickel ions from water using chitosan coated PVC beads. Biores. Technol, v. 100, p. 194-199, 2009.

VIJAYA, Y.;POPURI, S. R.; BODDU, V. M.; KRISHNAIAH, A. Modified chitosan and calcium alginate biopolymer sorbents for removal of nickel (II) through adsorption. Carbohydr. Polym., v. 72, p. $261-271,2008$.

WAN,M.W; KAN,C.C.; ROGEL,B.D.; DALIDA,M.L.P. Adsorption of copper (II) and lead (II) ions from aqueous solution on chitosan-coated sand. Carbohydr. Polym., v. 80, p. 891-899, 2010.

WESKA, R. F.; MOURA, J. M.; BATISTA, L. M.; RIZZI, J.; PINTO L. A. A. Optimization of deacetylation in the production of chitosan from shrimp wastes: Use of response surface methodology. J. Food Eng., v. 80, p. 749-753, 2007.

ZHANG, H.; NEAU, S. H. In vitro degradation of chitosan by a commercial enzyme preparation: Effect of molecular weight and degree of deacetylation. Biomaterials, v. 22, p. 1653-1658, 2001. 